\title{
A practical guide for medical teachers, 4th edition
}

- Title: A practical guide for medical teachers, 4th edition

- Authors: John A. Dent, Ronald M. Harden

- Publisher: Churchill Livingstone, 2013

- ISBN: 9780702045516

2001년 처음 출판되어 이미 지난 2008년 “의학교육: 이론 에서 실제까지”라는 번역본으로 국내에도 소개된 바 있는 “A practical guide for medical teachers"가 새로운 모습으로 출간되었다. 개정된 제4판에서는 최근 의학교육에서 집중 조 명되고 있는 다양한 주제들을 세계 각국 의학교육자들의 폭 넓은 경험과 전문지식을 통해 논의하여 의과대학 교수들의 관심을 불러일으킨다.

본문은 총 7개의 장으로 구성되어 있다. 의학교육의 새로운 지평을 논의하는 것으로 시작하는 제1장 Curriculum development는 교육과정을 계획하고 개발하는 원리와 방법을 소개하고 학부, 대학원, 졸업 후 교육과정을 실제적인 가이드 로 활용해도 좋을 만큼 구체적으로 안내하고 있다. 특히 다른 의학교육 지침서들에서는 접할 수 없었던 hidden curriculum을 별도로 다루고 있어 잠재적 교육과정에 대한 이해를 돕는다. 제2장 Learning situations는 강의를 포함하여 smallgroup teaching, clinical skills centre teaching, bedside teaching, ambulatory care teaching, peer-assisted learning, mentoring 등 다양한 학습장면을 언제, 누구에게, 어떻 게 적용하고 평가해야 가장 효과적인지 구체적인 전략과 함 께 안내하고 있다. 제3장 Educational strategies는 의학교육 이 왜 성과바탕교육(outcome-based education)으로 전환되 어야 하는지 그 필요성을 규명하고 problem-based learning, team-based learning, integrated learning 등의 전략을 소 개하고 있다. 이어 제4장 Tools and aids는 simulation, standardized patients, digital education, mobile learning 등 활용해 볼 만한 다양한 교육적 도구들을 소개한다. 제5장 은 basic sciences, clinical communication, ethics, pro-

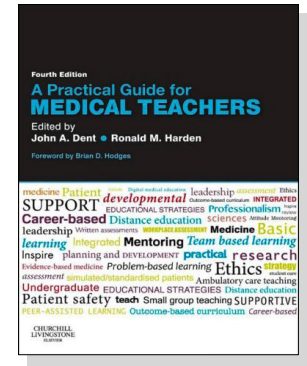

fessionalism, evidence-based medicine, patient safety 등 다양한 주제들을 어떻게 가르치고, 평가해야 하는지를 구체 적으로 안내해 주며, 제6장은 assessment의 개념을 정립하고, written, performance, workplace, portfolio 등 다양한 평 가 방법과 효과적인 피드백을 위한 원리를 구체적인 예시와 함께 소개한다. 또한 제 5 장에서는 객관적인 지표를 제시하기 어렵다고 여겨지고 있던 professionalism 평가에 대한 논의 를 진행하고 있어 많은 의과대학 교수에게 도움이 될 것이다. 이 책의 마지막 장인 제7장은 Staff and students이다. 이 장 은 우리나라 현재 상황을 고려하였을 때 다소 맞지 않는 부분 이 있기는 하지만 리더십, 학생선발, 학생들의 well-being을 위한 지원, 교육환경, 의학교육 연구 등 상당히 다양한 주제를 포함하고 있어 인상 깊게 읽을 수 있다.

이처럼 이 책은 폭 넓은 의학교육의 전(소) 영역을 다루면서

Korean J Med Educ 2015 Mar; 27(1): 55-56.

http://dx.doi.org/10.3946/kjme.2015.27.1.55

eISSN: $2005-7288$

(C) The Korean Society of Medical Education. All rights reserved.

This is an open-access article distributed under the terms of the Creative Commons Attribution Non-Commercial License (http://creativecommons.org/ licenses/by-nc/3.0/), which permits unrestricted non-commercial use, distribution, and reproduction in any medium, provided the original work is properly cited. 
도 현재 중요한 이슈와 트렌드를 놓치지 않고 핵심적인 주제 로 논의하여 현실감 있는 정보를 제공해 준다. 특히 방대한 정 보를 실제 활용이 가능한 수준으로 그 원리와 전략들을 소개 하고, 내일 수업에 바로 적용이 가능할 아이디어와 자료를 제 공해 주어 의과대학 교수에게 많은 도움을 줄 수 있을 것으로 기대한다. 끝으로 이 책의 서문에 Hodges 교수가 남긴 글로 리뷰를 마친다. "This marvelous book reminds us that, in the health professions, "We are all teaching and we are all learning."

조아라, 가톨릭대학교 의과대학 의학교육학과 A Ra Cho, Department of Medical Education, The Catholic University of Korea College of Medicine, Seoul, Korea 